\title{
Quantitative Study of Monetary Liquidity Impact on Inflation in China*
}

\author{
Zhou Mei, Yang Yuqing \\ College of Science, North China Univ. of Tech., 100144, Beijing, China \\ mzhou@ncut.edu.cn, yangyuqing009@163.com
}

\begin{abstract}
In order to measure the monetary liquidity quantitative impact on inflation in China, this paper will measure monetary liquidity from the liquidity of money supply and the currency circulation speed, by using Eviews 6.0 software to establish the regression analysis model, do the cointegration analysis, and establish the VAR and ECM model. The result shows that the liquidity of money supply increases with the consumer price index; and the circulation speed of money and consumer price index react to the liquidity of money supply together. Inflation

Index Terms - Monetary liquidity, Econometrics model, CLC: F830.53

\section{Research Background and Significance}

In recent years, inflation in China changes fiercely and excessive liquidity is undoubtedly an important reason for the effects of inflation. The damage of inflation on economic development, people's life and social stability would be devastating. Therefore, the study on monetary liquidity and inflation has very important practical significance.
\end{abstract}

\section{Index Selection and Statistical Analysis}

\section{A. Inflation Indicators Selection}

The indicators of inflation mainly include CPI, GDP deflator and producer price index (PPI). GDP deflator measures the degree of change in the price of all goods and services within a certain period. Although its coverage is the most extensive, our county has not announced the GDP deflator yet. PPI, another important price index published monthly in many countries, is to illustrate the price changes of capital goods, intermediate goods, raw materials and other commodities in different stages of production. But it does not reflect changes in the many kinds of services price. Therefore, compared GDP deflator and PPI, CPI is more valuable in measuring inflation, and, to some extent, it also can reflect the changes in PPI. So, in this paper, we will select CPI as an indicator measured. To unify measure indicator, it is necessary to convert monthly CPI to quarterly CPI. Due to the first month and the third month in a quarter are slightly affected by the quarters before and after, so quarterly CPI is calculated using the weighted method. In this paper, the weights are 0.3 , $0.4,0.3$. The quarterly CPI can be expressed in terms of the weights as

$$
\mathrm{CPI}=0.3 \mathrm{x}_{1}+0.4 x_{2}+0.3 x_{3} .
$$

where $x_{1}$ is the first month CPI value in a quarter, $x_{2}$ is the second month CPI value in the same quarter, and $x_{3}$ is the third month CPI value.

\section{B. Current liquidity Indicators Selection}

For monetary liquidity, we use two indicators to represent the ability of monetary liquidity.

1)Liquidity of Money Supply. It can be measured with the indicator $\mathrm{M}_{1} / \mathrm{M}_{2}$ which obtained based on currency liquidity. The higher liquidity in the money supply, then the stronger financial assets can be converted into cash.

2)Currency Circulation Speed. It can be measured with the indicator $\mathrm{M}_{2} / \mathrm{GDP}$ which obtained based on the median ability in monetary liquidity. The faster speed of currency circulation, indicating that currency unit can media more amount of physical economy, then, currency have a greater capacity to be a media.

\section{Empirical Analysis of Monetary Liquidity Impact on Inflation in China}

\section{A. Trend Analysis of M2/GDP}

$\mathrm{M}_{2} / \mathrm{GDP}$ trend plot have obvious seasonal trend. Therefore, it is necessary to remove seasonal effect. Here, we use Census X12 method in Eviews which moves average on a symmetrical Henderson to remove seasonal effect. Then, we make charts as follows (Figure 1):

M2/GDP_TC is a trend-cycle sequence which obtained after the removal of seasonal effect and irregular factors by Census X12. Compared with M2/GDP sequence, its line chart looks more smoothly, and the upward trend is very obvious. Wave-shaped M2/GDP_SF is the seasonal factor of M2/GDP. Irregularly shaped M2/GDP_IR is the irregular factors. An examination of Figure 2 shows that during 2000 and 2003, monetization process in China was extremely rapid. However, in years 2003-2008, with the rise of Foreign exchange problem caused by higher foreign exchange reserves, demand for basic currency extremely increased, which lead to serious problem of excess liquidity. To resolve the problem, we carried out tight monetary policy, limiting the rate of monetization of the economy. While in order to cope with the global financial crisis and prevent economy recession, loose monetary policy is implemented to stimulate economy.

\footnotetext{
${ }^{*}$ Science and Technology Development Plan Project of Beijing Education Commission (No.KM201310009013).
} 
M2/GDP_IR

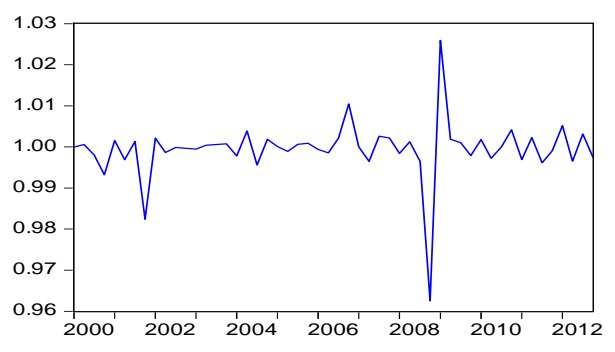

M2/GDP_SF

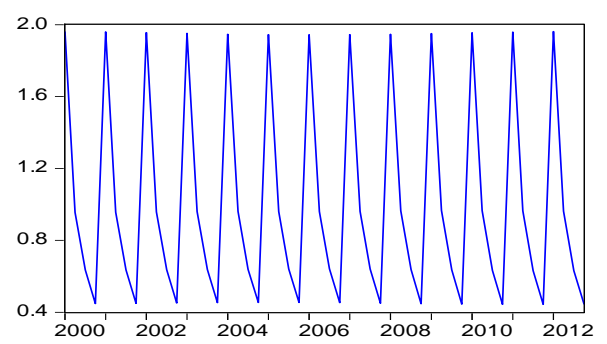

M2/GDP_SA

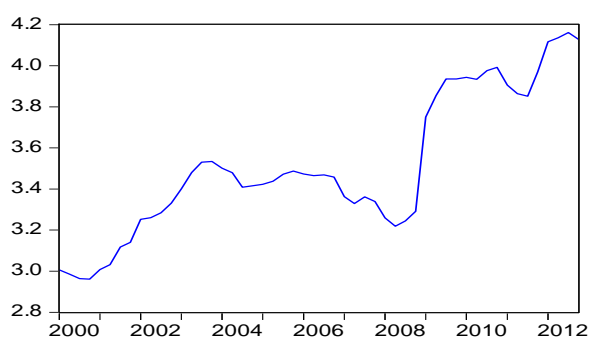

M2/GDP_TC

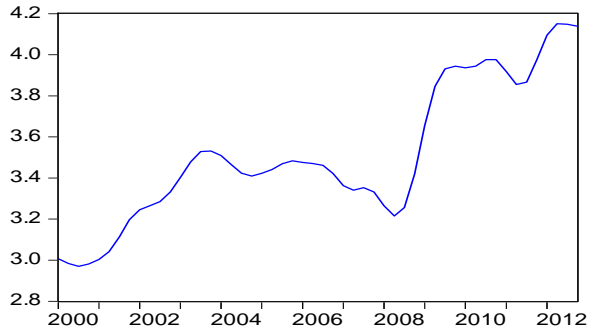

Fig. 1 Trend plot without seasonal effect

In mid-2008, monetary liquidity began to increase, indicating that the recent monetary policy has worked. If excessive liquidity exists, money supply $\left(\mathrm{M}_{2}\right)$ will greatly exceed the demand (nominal GDP). In other words, if increased money supply exceeds the level of economic development, or money demand sharply declines caused by weakening preferences of held savings, problem of excessive liquidity will arise. From Figure 1, it appears that money supply do significantly exceeds money demand, indicating obvious excessive liquidity. Government ought to pay attention to the problem, otherwise, economic growth will be blocked.

\section{B. Cointegration Test}

\section{1) Stationary Test}

Integration test results show that at $95 \%$ significant level, each $\mathrm{ADF}$ value is greater than the threshold value, indicating non-stationary. However, each first-order differential ADF value is less than the critical value, showing that tested variables are first-order sequence. Therefore, we can utilize cointegration test.

\section{2) Cointegration Test}

According to cointegration test results, we learn that trace test rejects the null hypothesis without cointegration at the 0.05 significant level. It can be considered to have only one cointegration among the variables, which also indicate that the long-term stable equilibrium relationship exists between currency liquidity and inflation. Therefore, we can establish regression models.

\section{Vector Autoregression Model}

Due to the used variables such as CPI, $\mathrm{M}_{1} / \mathrm{M}_{2}, \mathrm{M}_{2} / \mathrm{GDP}$ have certain seasonal trends, it is reasonable to consider the fourth-order lag as a variables and determine lag order according to the minimum value principle of AIC and SC. After repeated calculations, the first-order lag and the fourth-order lag are selected to be variables and at the same time, AIC and SC have the minimum value. The final model can be expressed as:

$$
\begin{aligned}
& {\left[\begin{array}{l}
C P I \\
M_{1} / M_{2} \\
M_{2} / G D P
\end{array}\right]_{t}=\left[\begin{array}{l}
0.445812 \\
0.234762 \\
0.182606
\end{array}\right]+\left[\begin{array}{ccc}
0.922205 & 0.182990 & -0.000340 \\
-0.134975 & 0.987919 & -0.000781 \\
-4.133062 & -4.355628 & -0.004802
\end{array}\right]\left[\begin{array}{c}
C P I \\
M_{1} / M_{2} \\
M_{2} / G D P
\end{array}\right]_{t-1}+} \\
& {\left[\begin{array}{ccc}
-0.241404 & -0.501770 & -0.000523 \\
-0.017868 & -0.172401 & -0.003034 \\
3.574233 & 5.244956 & 1.039193
\end{array}\right]\left[\begin{array}{c}
C P I \\
M_{1} / M_{2} \\
M_{2} / G D P
\end{array}\right]_{t-4}+\left[\begin{array}{c}
\varepsilon_{0} \\
\varepsilon_{1} \\
\varepsilon_{2}
\end{array}\right]_{t}}
\end{aligned}
$$

\section{Granger Causality Test}

Testing on VAR model with Granger Causality Test, the results are as follows: 
Table 1 Granger Causality Test results

\begin{tabular}{|l|l|l|l|}
\hline \multicolumn{5}{|l|}{ Dependent variable: CPI } & Chi-sq & df & Prob. \\
\hline Excluded & 10.63456 & 2 & 0.0049 \\
\hline M1/M2 & 0.432574 & 2 & 0.8055 \\
\hline M2/GDP & 11.08616 & 4 & 0.0256 \\
\hline All & Chi-sq & df & Prob. \\
\hline Dependent variable: M1/M2 & 2 & 0 \\
\hline Excluded & 23.52815 & 2 & 0 \\
\hline CPI & 65.84066 & 4 & 0 \\
\hline M2/GDP & 106.4272 & 4 & \\
\hline All & M2/GDP & & Prob. \\
\hline Dependent variable: & df & 0.0005 \\
\hline Excluded & Chi-sq & 2 & 0.1604 \\
\hline CPI & 15.13417 & 2 & 0 \\
\hline M1/M2 & 3.660691 & 4 & \\
\hline All & 27.40562 & & \\
\hline
\end{tabular}

Causality test results on VAR model show Granger Causality test statistics and the corresponding probability value each endogenous variable (i.e. the endogenous variable corresponding equation) to other endogenous variables in the model. From the above table, we can see that the value of $\chi^{2}$ statistics of the endogenous variable CPI to the endogenous variable $\mathrm{M}_{1} / \mathrm{M}_{2}$ is 10.63456 , and the corresponding probability value is 0.0049 . Therefore, at the 0.05 significant level, the variable $\mathrm{M}_{1} / \mathrm{M}_{2}$ can not be ruled out in the corresponding equation, namely, the variable $\mathrm{M}_{1} / \mathrm{M}_{2}$ is the Granger reason of the variable CPI. While the value of $\chi^{2}$ statistics of the endogenous variable $\mathrm{CPI}$ to the endogenous variable $\mathrm{M}_{2} / \mathrm{GDP}$ is 0.432574 , and the corresponding probability value is 08055 . Therefore, at the 0.05 significant level, the variable $\mathrm{M}_{2} / \mathrm{GDP}$ should be ruled out in the corresponding equation, namely, the variable $\mathrm{M}_{2} / \mathrm{GDP}$ is not the Granger reason of the variable CPI. At the same time, we also see that for the variable CPI, the value of $\chi^{2}$ statistics of combined significant test of the variables $\mathrm{M}_{1} / \mathrm{M}_{2}$ and $\mathrm{M}_{2} / \mathrm{GDP}$ is 11.08616 , and the corresponding probability is 0.0256 . Therefore, compared with lags of $\mathrm{M}_{1} / \mathrm{M}_{2}$ and $\mathrm{M}_{2} / \mathrm{GDP}$, the endogenous variable $\mathrm{CPI}$ is significant.

Similarly, we can see that both variables CPI and $\mathrm{M}_{2} / \mathrm{GDP}$ are the Granger reason of the variable $\mathrm{M}_{1} / \mathrm{M}_{2}$, and compared with lags of $\mathrm{CPI}$ and $\mathrm{M}_{2} / \mathrm{GDP}$, the endogenous variable $\mathrm{M}_{1} / \mathrm{M}_{2}$ is significant. While the variable CPI is the Granger reason of the variable $\mathrm{M}_{2} / \mathrm{GDP}$, but the variable $\mathrm{M}_{1} / \mathrm{M}_{2}$ is not the Granger reason of the variable $\mathrm{M}_{2} / \mathrm{GDP}$ and compared with lags of $\mathrm{M}_{1} / \mathrm{M}_{2}$ and $\mathrm{CPI}$, the endogenous variable $\mathrm{M}_{2} / \mathrm{GDP}$ is significant.

From the above results, it can be considered that change of CPI lead to change in $\mathrm{M}_{2} / \mathrm{GDP}$, while the change of CPI is caused by the change of $\mathrm{M}_{1} / \mathrm{M}_{2}$. In addition, the change of CPI and $\mathrm{M}_{2} / \mathrm{GDP}$ would react to the change of $\mathrm{M}_{1} / \mathrm{M}_{2}$ together. It means that excessive money supply leads to inflation and inflation will lead to faster circulation velocity, while faster circulation and inflation will react to money supply, resulting in increasing money supply, and eventually evolving into a vicious cycle. E.Lag Exclusion Test in the VAR Model

Doing lag exclusion test for estimated VAR model, the results show that all $\mathrm{p}$-values of lags are very small, indicating that in CPI equation, $\mathrm{M}_{1} / \mathrm{M}_{2}$ equation, and $\mathrm{M}_{2} / \mathrm{GDP}$ equation of VAR model, all the first-order and the forth order lagged endogenous variables are significant respectively. Meanwhile, all the first-order and the forth-order lagged endogenous variables in VAR model are significant respectively.

\section{Conclusions and Suggestions}

The main conclusions of this paper are as follows:

1. Monetary liquidity has two attributes, namely, monetary liquidity and currency medium capacity which can be represented by the liquidity of money supply $M_{1} / M_{2}$ and currency circulation velocity $\mathrm{M}_{2} / \mathrm{GDP}$ respectively.

2. A cointegration relationship exists between currency liquidity and inflation, namely, they have real long-term balanced relationship.

3. The causal relationship between monetary liquidity and inflation shows different causal relationship. Monetary supply liquidity $\mathrm{M}_{1} / \mathrm{M}_{2}$ leads to the change of CPI which lead to the change of money circulation velocity. At the same time, the change of CPI and $\mathrm{M}_{2} / \mathrm{GDP}$ would react to the change of $\mathrm{M}_{1} / \mathrm{M}_{2}$ together.

4. In CPI equation with t period, the CPI coefficient of the $\mathrm{t}-1$ period is 0.922205 , and the coefficients of $\mathrm{M}_{1} / \mathrm{M}_{2}$ and $\mathrm{M}_{2} / \mathrm{GDP}$ are 0.182990 , -0.000340 respectively. While the coefficients of CPI, $\mathrm{M}_{1} / \mathrm{M}_{2}, \mathrm{M}_{2} / \mathrm{GDP}$ of $\mathrm{t}-4$ period are $-0.241404,-050177,-0.000523$ which mean the corresponding change units of CPI in the $t$ period with changes of each index in one unit.

\section{References}

[1] Li Zhanfeng and Chen Yu: "Quantitative study of monetary liquidity impact on inflation in china -- Based on the demonstration of time-varying parameter model", "economictics research", 2010(8), pp.21-24.

[2] Li Qian, Yang Zhike: "the money supply fluctuation on the impact of inflation", "price weekly", 2010(10), pp.10-12.

[3] Yang Cunliang: "monetary liquidity and inflation", "financial theory and practice", 2008(11), pp.44-46.

[4] Liu Zuanshi, Li Dan: "empirical analysis of the relationship between the excessive liquidity and inflation in China", "modern economic science", 2008 (9), vol30, pp. 33-36.

[5] He Keng: "excessive liquidity, inflation and monetary policy", "theory and practice of Finance and economics", 2009 (1), pp. 11-13.

[6] Li Yanqing: "on China's currency liquidity surplus problem and related policy choice", "reform and opening", 2012(2), pp.11-14.

[7] Hu Shutao: "analysis the current situation and reasons of Chinese economic inflation -- Based on of monetary demand theory", "Huazhong Normal University Journal of postgraduates", 2008(4), pp.2-4.

[8] Yi Jianhang, Xie Shiyu and Liu Zonghua: "our M1/M2 (1978-2002): the long-term trend and cycle fluctuations,", "Journal of Central University of Finance and Economics", 2003 (11), pp. 2-3. 